DOI 10. 18307/2021. 0514

(c) 2021 by Journal of Lake Sciences

\title{
湖滨带芦苇恢复过程中沉积物氮赋存形态及含量变化: 以巢湖为例“
}

余居华 ${ }^{1,2,3 * *}$, 王乐豪 ${ }^{2}$, 康得军 ${ }^{2}$, 郑恭毅 ${ }^{2}$, 郭宝玲 ${ }^{1}$, 钟继 承 $^{3}$, 郑祥洲 ${ }^{1}$, 张玉树 ${ }^{1}$, 蔡远松 ${ }^{4}$, 丁 洪 $^{1}$

( 1 : 福建省农业科学院土壤肥料研究所,福州 350013)

$(2$ : 福州大学土木工程学院, 福州 350000$)$

(3: 中国科学院南京地理与湖泊研究所湖泊与环境国家重点实验室,南京 210008)

( 4 : 福建省安溪县蓬莱林业工作站, 泉州 362402$)$

摘 要: 水生植被对于维持水生态系统结构和功能稳定性具有举足轻重的作用, 而重建水生植物被认为是污染湖泊生态 修复的重要手段. 氮素是水生态系统重要的限制性元素之一, 根着挺水植物生长发育无疑将深刻地影响着沉积物氮的迁 移转化过程, 但水生植物不同生长阶段对沉积物氮的需求和植物代谢强度均不同, 目前对挺水植物完整生长过程中沉积 物氮组分及含量变化认识仍十分不足. 本研究通过为期 $120 \mathrm{~d}$ 的沉积物柱芯培养和水槽模拟试验, 探究巢湖芦苇恢复完 整生长过程中沉积物总氮 (TN)、无机氮 (TIN) 与可转化态氮 (TF-N) 的变化及其关键调控因子. 结果表明, 芦苇完整生长 过程将持续激发沉积物氮活性, 沉积物 TIN 与 TF-N 含量逐渐增加, 而沉积物 TN 和非可转化态氮 ( NTF-N) 含量显著降低. 模拟试验期间, 指数型增长的芦苇生物量提高了沉积物铵态氮 $\left(\mathrm{NH}_{4}^{+}-\mathrm{N}\right)$ 和硝态氮 $\left(\mathrm{NO}_{3}^{-}-\mathrm{N}\right)$ 含量, 但亚硝态氮 $\left(\mathrm{NO}_{2}^{-}-\mathrm{N}\right)$ 含 量却逐渐降低; 与第 0 天相比, 第 120 天沉积物离子交换态氮 (IEF-N)、碳酸盐结合态氮 ( CF-N)、铁锰氧化态氮( IMOF-N) 和有机态及硫化物结合态氮 ( OSF-N) 含量分别增加了 $1.10 、 3.40 、 3.60$ 和 1.40 倍, 这主要受芦苇吸收利用、根系代谢强化 根际沉积物氧化还原电势和改变 $\mathrm{pH}$ 微环境共同驱动. 在第 120 天, 沉积物 $\mathrm{NH}_{4}^{+}-\mathrm{N}$ 和 $\mathrm{NO}_{3}^{-}-\mathrm{N}$ 含量急剧升高, 分别是第 90 天的 9.43 和 2.22 倍, 表明芦苇衰亡调落过程将向沉积物释放大量的 TIN, 故需要综合采取湖泊物理一生态工程手段来有 效管控芦苇枯落物,从而提升水生植被修复效果并构建长效稳态机制.

关键词: 水生植物;沉积物;氮; 富营养化湖泊;生态修复;巢湖

\section{Temporal changes in fractions and loading of sediment nitrogen during the holistic growth period of Phragmites australis in littoral Lake Chaohu, China*}

Yu Juhua $^{1,2,3 * *}$, Wang Lehao ${ }^{2}$, Kang Dejun ${ }^{2}$, Zheng Gongyi ${ }^{2}$, Guo Baoling ${ }^{1}$, Zhong Jicheng ${ }^{3}$, Zheng Xiangzhou $^{1}$, Zhang Yushu ${ }^{1}$, Cai Yuansong ${ }^{4} \&$ Ding Hong $^{1}$

(1: Institute of Soil and Fertilizer, Fujian Academy of Agricultural Sciences, Fuzhou 350013, P.R.China)

(2: College of Civil Engineering, Fuzhou University, Fuzhou 350000, P.R.China)

(3: State Key Laboratory of Lake Science and Environment, Nanjing Institute of Geography and Limnology, Chinese Academy of Sciences, Nanjing 210008, P.R.China)

(4: Penglai Forestry Station of Anxi County, Quanzhou 362402, P.R.China)

Abstract: Aquatic vegetation's important structuring function in shallow freshwater ecosystems has been increasingly recognized as an important ecological restoration measure to rehabilitate heavily polluted water. Nitrogen $(\mathrm{N})$ is one of the most important limiting elements in aquatic ecosystems, and the growth of rooted aquatic macrophytes profoundly affected sediment $\mathrm{N}$ biogeochemistry. Due

* 2020-08-26 收稿; 2020-10-19 收修改稿.

国家自然科学基金项目(51709183)、中国博士后科学基金项目(2017M611862)、福建省属公益科研院所基金项目 (YC2019007,ZYTS2019016,STIT2017-1-9) 和福建省农业科学院对外合作项目 (DEC2019-05, DEC2020-05) 联合资 助.

** 通信作者;E-mail: juhuayu1984@ gmail.com. 
to variable requirements of $\mathrm{N}$ for the different growth phases of Phragmites australis, as well as metabolism extensity of macrophytes is changing, it is thereby unclear how the holistic growth period of aquatic macrophytes affects sediment $\mathrm{N}$ cycling in eutrophic lakes. In this study, combined intact sediment core microcosm batch experiment and flume modelling, a 120-d simulation study was conducted to investigated changes of total nitrogen ( TN), inorganic nitrogen and total exchangeable form of nitrogen ( TF-N) in sediments surrounding rhizosphere of $P$. australis during the whole growth of $P$. australis. The results showed a priming effect of sediment $\mathrm{N}$ by $P$. australis was observed, with the contents of total inorganic nitrogen ( TIN) and TF-N in sediments gradually increasing, while TN and non-exchangeable form of nitrogen ( NTF-N) declining. During the experiment, the exponential-increasing biomass of $P$. australis remarkably promoted the contents of ammonium nitrogen $\left(\mathrm{NH}_{4}^{+}-\mathrm{N}\right)$ and nitrate nitrogen $\left(\mathrm{NO}_{3}^{-}-\mathrm{N}\right)$, but not for nitrite nitrogen $\left(\mathrm{NO}_{2}^{-}-\mathrm{N}\right)$. Compared with the initial values of TF-N, on day 120, the contents of the exchangeable form ( IEF-N), carbonate form ( CF-N), iron-manganese oxides form ( IMOF-N) and organic matter-sulfide form ( OSF-N) in surface sediments increased by $1.10,3.40,3.60$ and 1.40 times. This phenomenon could be attributed to the root metabolisms-driven redox condition and $\mathrm{pH}$ changes in rhizospheric microsites. On day 120 , the contents of $\mathrm{NH}_{4}^{+}-\mathrm{N}$ and $\mathrm{NO}_{3}^{-}-\mathrm{N}$ in sediments dramatically increased, of which were 9.43 and 2.22 times in comparison with those on day 90, suggesting that massive TIN was released into the sediments caused by senescent processes of litter from $P$. australis. In brief, to improve the restoration efficiency and long-term stabilization of pollution control, it is of more significance to adopt comprehensive lake physico-ecological engineering measures to manage the litters derived from $P$. australis.

Keywords: Aquatic macrophytes; sediments; nitrogen; eutrophic lakes; ecological restoration; Lake Chaohu

随着社会经济快速发展, 伴随大量污染物进人到水环境, 造成受纳水体污染程度加重并引发全球湖库 水生态系统水生植被分布面积下降,甚至在局部水域出现大面积消亡 ${ }^{[1]}$. 富营养化是一个世界性的水环境 问题 ${ }^{2-3]}$, 我国有 $80 \%$ 的湖泊处于富营养化状态. 对 67 个主要湖泊调查发现, $26.9 \%$ 为中营养型湖泊, $73.1 \%$ 为富营养湖泊 ${ }^{[4]}$. 叠加水体营养盐输人和水生植被退化严重, 造成藻类大量增殖而出现水华现象 ${ }^{[5-6]}$, 进而 导致富营养化湖泊从清水态的草型生态系统向浊水态藻型生态系统转换 ${ }^{[7-8]}$, 加速了湖泊沼泽化进程, 损害 了湖泊水体生态和社会经济服务功能 ${ }^{[9]}$. 因此, 在退化湖泊水生态系统修复过程中, 合理规划开展水生植被 恢复与重建被认为是改善水质条件和维持湖泊生态系统结构和功能稳定性的重要修复措施 ${ }^{[1,10]}$.

水生植被是水生态系统中的重要组成部分, 对其进行恢复可以改变湖泊水体氮、磷等生源要素的生物 地球化学循环过程, 其中根着挺水植被主要从沉积物中获取营养物质, 因此更加剧烈地影响着湖泊沉积物 氮、磷迁移转化过程 ${ }^{[10]}$. 氮是水生态系统重要的限制性元素之一, 关于水生植被恢复对沉积物氮赋存形态 及含量的影响, 重点关注植被恢复后沉积物总氮 (TN) 含量、无机氮 (TIN) 含量及其形态变化 ${ }^{[11]}$, 往往忽略 了植被恢复过程沉积物可转化态氮 ( TF-N) 变化规律的探究. 研究发现沉水植物的生长能够降低沉积物的总 氮含量, 降幅为 $43.5 \% \sim 59.0 \%{ }^{[12-13]}$; 水生植被恢复使得沉积物中铵态氮 $\left(\mathrm{NH}_{4}^{+}-\mathrm{N}\right)$ 含量降幅为 $75.0 \%$ $87.4 \%^{[14-15]}$, 而硝态氮 $\left(\mathrm{NO}_{3}^{-}-\mathrm{N}\right)$ 含量降幅高达 $96.5 \%^{[15]}$. 其次, 大多数研究聚焦沉水植被恢复过程某个特定 阶段对沉积物氮组分及含量的影响,包先明等 ${ }^{[16]}$ 发现沉水植物生长阶段降低了沉积物 $\mathrm{TN}$ 和 $\mathrm{NH}_{4}^{+}-\mathrm{N}$ 含量, 而根系泌氧增强沉积物硝化过程提高了 $\mathrm{NO}_{3}^{-}-\mathrm{N}$ 含量; 胡红伟等 ${ }^{[17]}$ 发现芦苇、菖蒲调亡促使沉积物 $\mathrm{NH}_{4}^{+}-\mathrm{N}$ 含 量呈上升趋势, 而 $\mathrm{NO}_{3}^{-}-\mathrm{N}$ 含量出现下降, 亚硝态氮 $\left(\mathrm{NO}_{2}^{-}-\mathrm{N}\right)$ 含量呈先升高后降低的趋势. 但是, 由于水生植 被不同生长阶段对营养盐需求和植物代谢强度均不同 ${ }^{[18]}$, 目前对于水生植被恢复完整生长过程中沉积物氮 变化特征的认识仍十分不足, 特别是极易参与到沉积物氮循环过程的 TF- $\mathrm{N}$ 组分及其含量的变化规律. 目 前, 仅少数研究, 如王圣瑞等 ${ }^{[19]}$ 和孔祥龙等 ${ }^{[15]}$ 研究发现沉水植物整个生命周期降低了沉积物 TN 和 TIN 含 量, 但关于挺水植物完整生长过程对沉积物 TF- $\mathrm{N}$ 的影响认识仍很缺乏, 这极可能导致水生植物恢复在退化 湖泊生境修复工程中的生态效果评估产生偏差. 因此, 为准确评价水生植被恢复对水生态系统沉积物氮含 量及形态的影响和修复效果, 迫切需要进一步探究水生植被完整生长周期对沉积物 TN TF-N 与 TIN 形态及 含量的影响及其关键驱动因子.

本研究通过沉积物柱芯培养和水槽模拟实验, 选择巢湖挺水植物土著优势种——芦苇为受试植物, 完 整模拟了芦苇恢复的整个生长过程, 旨在研究芦苇完整生长过程中湖泊沉积物 TN 、TIN 与 TF-N 含量及形态 的转化时间变异规律, 试图探明芦苇恢复完整生长过程中沉积物氮组分及含量的驱动机制及关键调控因 
子,以期为退化湖泊和人工景观水体植被重建与恢复提供科学依据和技术支撑.

\section{1 材料与方法}

\section{1 样品采集及预处理}

近年来,不断的外源输人加剧了巢湖水体富营养化. 本研究样品采集于我国巢湖污染严重的西北部汇 流湾滨岸带 (图 1). 由于巢湖水生植被优势物种以芦苇为主 ${ }^{[20]}$, 且挺水植物受水体透明度影响小, 在重污染 水体中栽种的存活率高, 加上退化湖泊水体通常选择挺水植物先对退化滨岸进行修复的前期成功实践案 例, 故本研究的受试植物选择巢湖本地优势植物芦苇. 芦苇采集点位的具体坐标为 $31^{\circ} 42^{\prime} 4.76^{\prime \prime} \mathrm{N}, 117^{\circ} 21^{\prime}$ $43.49^{\prime \prime} \mathrm{E}$, 选取长势良好, 生长一致的芦苇幼苗 (株高约 $10 \mathrm{~cm}$ 、直径 $1 \mathrm{~cm}$ ), 连根挖起并立刻洗净芦苇表面的 污泥,装人到 $80 \mathrm{~L}$ 的塑料桶中, 并在 $5 \mathrm{~h}$ 内带回实验室.

沉积物采集点位与芦苇相同, 采用彼得森采样器采集巢湖西部重污染湾区滨岸表层沉积物, 同步采集 原点位的底层上覆水体 (图 1). 为最大限度降低沉积物空间异质性的干扰, 将采集的沉积物带回实验室进 行篮分 (孔径为 $0.6 \mathrm{~mm}$ ), 篮除大颗粒物质以及大型水生动物, 并对篮分过后的沉积物进行充分匀化处理. 为防止玻璃管中的沉积物受上覆水挤压而出现下沉的情况, 将充分匀化的沉积物装人到有机玻璃管中进行 为期半个月的预培养 (高 $\times$ 内径为 $25 \mathrm{~cm} \times 18 \mathrm{~cm}$ ), 将出现沉降的玻璃管沉积物厚度最终调整为 $18 \mathrm{~cm}$. 在实 验开始前, 将生物量及形态相似的芦苇根茎挑选出来, 而后将芦苇根茎插人到距沉积物表层 $5 \mathrm{~cm}$ 深处进行 定植; 其次, 根据前期野外调查获得的芦苇密度, 每个微环境有机玻璃管中芦苇栽植密度为 160 株 $/ \mathrm{m}^{2}$. 将上 述处理好的样品全部放人到水槽 (长 $\times$ 宽 $\times$ 高 $=220 \mathrm{~cm} \times 110 \mathrm{~cm} \times 75 \mathrm{~cm}$ ) 中, 预先平衡培养 $15 \mathrm{~d}$, 并及时补种死 亡的芦苇幼苗,确保芦苇栽种密度和长势情况一致,减少系统误差.

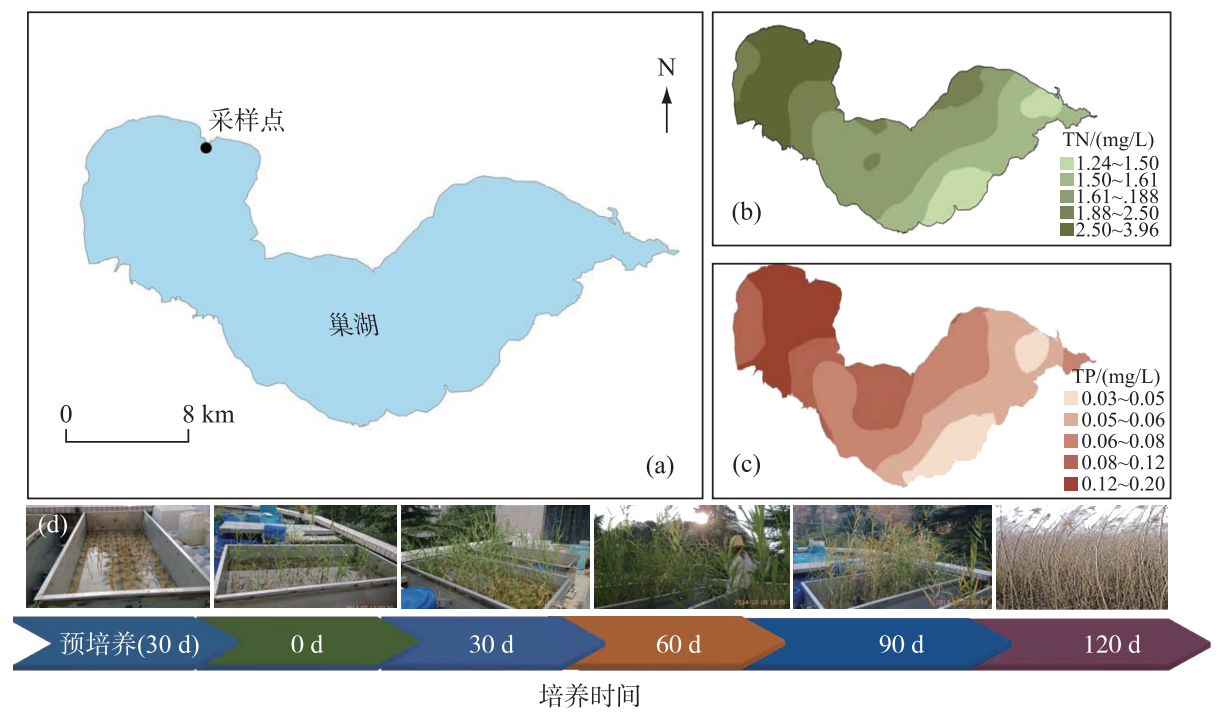

图 1 采样点位置 $(\mathrm{a})$ 、巢湖上覆水体总氮 (b) 和总磷 $(\mathrm{c})$ 浓度空间变异及 芦苇恢复完整生长过程模拟实验 $(\mathrm{d})$

Fig.1 Location of sampling site (a), spatial distributions of TN (b) and TP (c) concentrations in overlying water across Lake Chaohu, and overall growing period of $P$. australis in this simulation study (d)

\section{2 实验设计}

本实验利用自制循环水槽进行模拟, 实验水深设置为 $40 \mathrm{~cm}$, 真实地模拟巢湖滨岸水深原位条件. 为能 较好地模拟巢湖水体的营养状况, 实验过程中每 $30 \mathrm{~d}$ 更换一次湖水. 整个模拟实验持续开展 $120 \mathrm{~d}$, 具体采 样时间设计在第 $0 、 30 、 60 、 90 、 120$ 天分别称量芦苇总生物量、地下部生物量和细根生物量, 同步采集芦苇根 区表层 0 10 cm 沉积物样品. 每一次实验均随机抽取 4 个平行样品进行分析. 采集结束后, 立刻用自来水将 
芦苇根部清洗干净, 同步收集并保存泥柱中的芦苇调落物, 并将收集到的芦苇调落物分别计人到相应批次 的芦苇生物量中, 避免芦苇枯落物腐解而向水体释放养分, 从而造成实验结果出现偏差. 将每次采集到的表 层沉积物事先去除动植物碎屑和大颗粒石块,冷冻干燥并研磨过篮 (孔径为 $0.150 \mathrm{~mm}$ ), 保存待测.

\section{3 沉积物性质分析}

结合岛津紫外一可见分光光度计 (UV3600, Japan), 沉积物中的 TN、总磷 (TP) 含量采用过硫酸盐消化 法 ${ }^{[21]}$ 进行测定, $\mathrm{NO}_{3}^{-}-\mathrm{N}$ 含量采用饱和硫酸钻提取一紫外分光光度法测定, $\mathrm{NH}_{4}^{+}-\mathrm{N}$ 含量采用纳氏试剂光度法 测定, 亚硝态氮 $\left(\mathrm{NO}_{2}^{-}-\mathrm{N}\right)$ 含量采用重氮偶氮分光光度法测定. 沉积物在 $105^{\circ} \mathrm{C}$ 条件下烘 $24 \mathrm{~h}$ 至恒重测定含 水率, 孔隙率与容重采用金属环刀法测定, 有机碳含量的测定采用 $\mathrm{K}_{2} \mathrm{Cr}_{2} \mathrm{O}_{7}-\mathrm{H}_{2} \mathrm{SO}_{4}$ 油浴氧化 $\mathrm{FeSO}_{4}$ 滴定法. 沉积物 $\mathrm{pH}$ 利用雷磁 $\mathrm{pH}$ 计进行测定, 沉积物铁、铝和钙含量通过硝解后利用电感耦合等离子体发射光谱 (Agilent Technologies, Waldbronn, Germany)进行分析.

沉积物氮形态分析综合了马红波等 ${ }^{[22]}$ 和赵海超等 ${ }^{[23]}$ 提出的化学连续浸提法, 将 TF-N 划分为 4 种形 态, 分别为: 离子交换态氮 (IEF-N)、碳酸盐结合态氮 ( CF-N)、铁锰氧化态氮 ( IMOF-N) 以及有机态和硫化物 结合态氮 (OSF-N). 简要的提取过程为: 取 $1 \mathrm{~g}$ 沉积物加人 $1 \mathrm{~mol} / \mathrm{L} \mathrm{MgCl}_{2}$, 在 $25^{\circ} \mathrm{C}$ 条件下浸提 $2 \mathrm{~h}$ 获得离子 交换态氮 ( IEF-N) ; 往残渣中加人 $\mathrm{HAc}-\mathrm{NaAc}(\mathrm{pH}=5)$, 在 $25^{\circ} \mathrm{C}$ 条件下浸提 $6 \mathrm{~h}$ 得到碳酸盐结合态氮 ( CF-N $)$; 接着向残渣中加人 $0.1 \mathrm{~mol} / \mathrm{L} \mathrm{NaOH}$, 在 $25^{\circ} \mathrm{C}$ 条件下浸提 $17 \mathrm{~h}$ 得到铁镇氧化态氮 ( IMOF-N); 加人 $\mathrm{K}_{2} \mathrm{~S}_{2} \mathrm{O}_{8}$ (碱 性), 在 $115^{\circ} \mathrm{C}$ 条件下浸提 $1 \mathrm{~h}$ 获得有机态和硫化物结合态氮 ( OSF-N), 上述步骤浸提出来的氮统称为 TF-N. 水样经 $0.45 \mu \mathrm{m}$ 玻璃纤维滤膜 (Whatman GF/C) 抽滤后采用流动注射分析仪 (Skalar-SA1000) 测定不同提取 液中的 $\mathrm{NO}_{3}^{-}-\mathrm{N} 、 \mathrm{NH}_{4}^{+}-\mathrm{N}$ 和 $\mathrm{NO}_{2}^{-}-\mathrm{N}$ 浓度, 沉积物 $\mathrm{TN}$ 含量与 TF-N 含量的差值则为非可转化态氮 ( NTF-N) 含量. 沉积物溶解氧剖面采用微电极系统 (Unisense, Denmark) 进行测定. 利用百分之一电子天平来测定芦苇总生 物量、地下部生物量和细根生物量的鲜重.

\section{4 数据处理与统计分析}

借助 SPSS 26.0(SPSS, USA) 和 Excel 2018(Microsoft, USA) 软件进行数据统计分析, 利用 Origin 8.5 软 件(OriginLab, Northampton, MA, USA) 绘图. 采用单因素方差 (ANOVA) 分析沉积物溶解氧侵蚀深度、TIN 和各 TF-N 含量变化的差异显著性; 其次, 利用单因素方差 ( ANOVA) 分析芦苇总生物量、地下部生物量和细 根生物量随时间变化的差异显著性. 选择 Pearson 相关分析检验沉积物 TIN TF-N 含量与芦苇总生物量、地 下生物量和细根生物量之间的相关性是否达到显著水平.

\section{2 结果}

\section{1 沉积物溶解氧侵蚀剖面变化特征}

应用于长期水槽模拟实验的沉积物基本理化性质如表 1 所示, 其中沉积物 TN 含量为 $2325 \mathrm{mg} / \mathrm{kg}$, 按湖 泊底泥环保疏浚标准来看, 沉积物氮污染程度属于重污染沉积物类型 ${ }^{[24]}$.与此同时, 同步分析了芦苇整个 生长过程中沉积物一水微界面溶解氧侵蚀深度在第 $0 、 60$ 和 120 天的时间变化规律 (图 2). 结果表明, 界面 溶解氧的侵蚀深度随培养时间推移显著增大 $(P<0.05)$, 溶解氧侵蚀深度在第 0 天达到 $4000 \mu \mathrm{m}$, 在第 60 天 达到 $5800 \mu \mathrm{m}$, 而在第 120 天溶解氧侵蚀深度甚至扩大到表层沉积物 $10000 \mu \mathrm{m}$ 位点.

表 1 模拟实验中沉积物基本理化性质

Tab.1 Physical and chemical properties of sediments applied in this simulation study

\begin{tabular}{cccccccccc}
\hline $\begin{array}{c}\text { 含水率/ } \\
\%\end{array}$ & $\begin{array}{c}\text { 孔隙率/ } \\
\%\end{array}$ & $\mathrm{pH}$ & $\begin{array}{c}\text { 容重/ } \\
\left(\mathrm{g} / \mathrm{cm}^{3}\right)\end{array}$ & $\begin{array}{c}\text { 总有机碳/ } \\
(\mathrm{g} / \mathrm{kg})\end{array}$ & $\begin{array}{c}\text { 总氮/ } \\
(\mathrm{mg} / \mathrm{kg})\end{array}$ & $\begin{array}{c}\text { 总磷/ } \\
(\mathrm{mg} / \mathrm{kg})\end{array}$ & $\begin{array}{c}\text { 铁/ } \\
(\mathrm{g} / \mathrm{kg})\end{array}$ & $\begin{array}{c}\text { 铝/ } \\
(\mathrm{g} / \mathrm{kg})\end{array}$ & $\begin{array}{c}\text { 钲/ } \\
(\mathrm{g} / \mathrm{kg})\end{array}$ \\
\hline 52.8 & 71.4 & 5.24 & 1.89 & 6.34 & 2325 & 425 & 43.1 & 85.7 & 38.8 \\
\hline
\end{tabular}

\section{2 沉积物总氮与无机氮含量的时间变化规律}

为探明芦苇完整生长过程中沉积物氮含量及形态的时间变化规律, 本研究选择在培养实验的第 $0 、 30$ 、 $60 、 90$ 和 120 天分析沉积物 TN 和 TIN 含量变化, 其中 TIN 形态包括 $\mathrm{NH}_{4}^{+}-\mathrm{N} 、 \mathrm{NO}_{3}^{-}-\mathrm{N} 、 \mathrm{NO}_{2}^{-}-\mathrm{N}$ ( 图 3). 结果表 


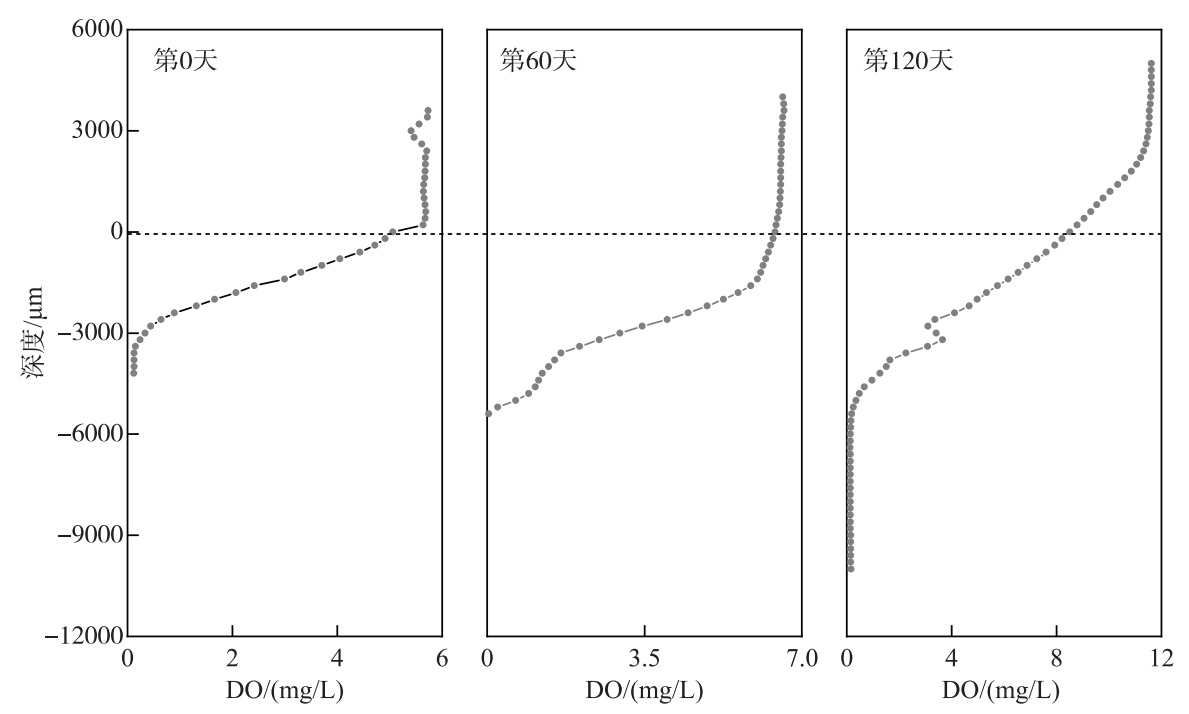

图 2 芦苇根际沉积物溶解氧侵蚀剖面时间变化规律

Fig.2 Depth profiles of DO penetration in surface sediments on day 0, day 60 and day 120 during the entire course of incubation experiment

明, 随芦苇恢复时间延长, 沉积物 TN 含量大致呈现递减趋势, 第 0 天沉积物 TN 含量最大, 为 $2325 \mathrm{mg} / \mathrm{kg}$; 实 验结束时 (第 120 天) 达到极小值, 对比初始值降低了 $52.1 \%$. 值得注意的是,第 30 天沉积物 TN 含量出现断 崖式下降, 减少幅度达到 $45.5 \%$, 而后出现略微增加, 在第 90 天 TN 含量为 $1333 \mathrm{mg} / \mathrm{kg}$. 沉积物 TIN 含量呈 现“漏斗状” 变化特征, 从第 0 天至第 90 天逐渐降低,降低幅度为 $20.0 \%$; 但在第 120 天, TIN 含量突然大幅 攀升, 为第 0 天 TIN 含量的 2.10 倍. 统计分析表明, 沉积物 TIN 含量的时间变化主要受控于沉积物 $\mathrm{NO}_{3}^{-}-\mathrm{N}$ 和 $\mathrm{NH}_{4}^{+}-\mathrm{N}$ 含量的变化 $(P<0.01)$.

通过深人分析沉积物各 TIN 形态含量的时间变化, 从 TIN 含量绝对值大小排列顺序来看, 依次为 $\mathrm{NO}_{3}^{-}-\mathrm{N}>\mathrm{NH}_{4}^{+}-\mathrm{N}>\mathrm{NO}_{2}^{-}-\mathrm{N}$ (图 3b). 在整个培养实验过程中, 沉积物 $\mathrm{NO}_{3}^{-}-\mathrm{N}$ 和 $\mathrm{NH}_{4}^{+}-\mathrm{N}$ 含量时间变化规律与 $\mathrm{TIN}$ 高度一致,除第 60 天外, 沉积物 $\mathrm{NO}_{3}^{-}-\mathrm{N}$ 含量从第 0 天至第 90 天逐渐降低, 并在第 120 天达到极大值 (76.6 $\mathrm{mg} / \mathrm{kg}$ ) ; 对比沉积物 $\mathrm{NH}_{4}^{+}-\mathrm{N}$ 的初始含量, 在第 90 天 $\mathrm{NH}_{4}^{+}-\mathrm{N}$ 含量降低了 $76.9 \%$, 而第 120 天 $\mathrm{NH}_{4}^{+}-\mathrm{N}$ 含量为初 始含量的 2.20 倍. 沉积物 $\mathrm{NO}_{2}^{-}-\mathrm{N}$ 含量是所有 TIN 形态中绝对值最低的, 为 $0.139 \sim 0.459 \mathrm{mg} / \mathrm{kg}$, 其随时间变 化趋势与 $\mathrm{NO}_{3}^{-}-\mathrm{N}$ 相反.
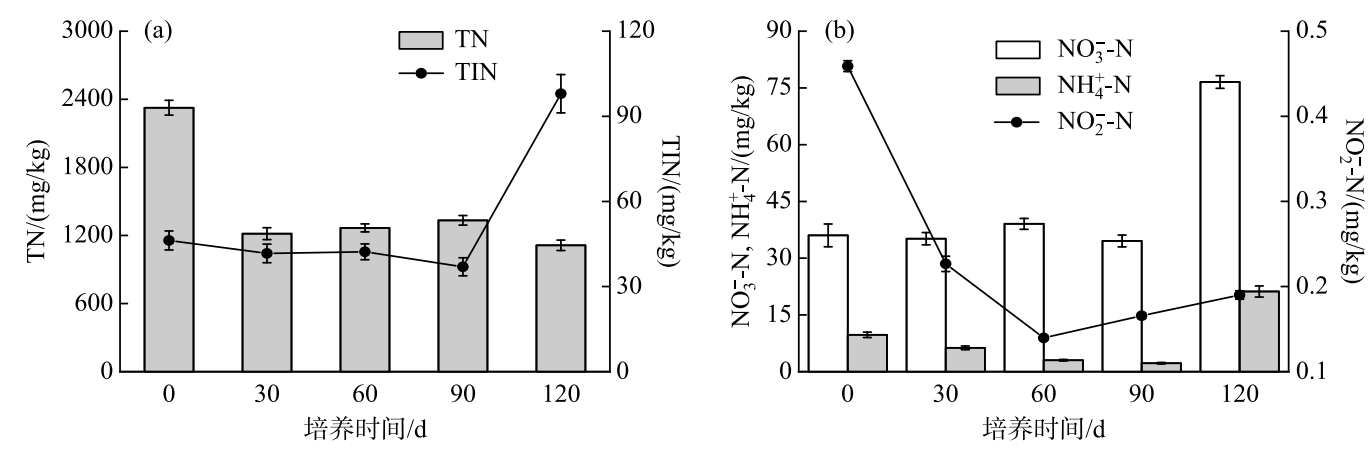

图 3 芦苇根际表层沉积物 $(0 \sim 10 \mathrm{~cm}) \mathrm{TN}$ 、TIN 含量 $(\mathrm{a})$ 和 $\mathrm{NO}_{3}^{-}-\mathrm{N} 、 \mathrm{NH}_{4}^{+}-\mathrm{N} 、 \mathrm{NO}_{2}^{-}-\mathrm{N}$ 含量 $(\mathrm{b})$ 变化规律

Fig. 3 Variations of TN, TIN contents (a) and $\mathrm{NO}_{3}^{-}-\mathrm{N}, \mathrm{NH}_{4}^{+}-\mathrm{N}, \mathrm{NO}_{2}^{-}-\mathrm{N}$ contents (b) in the surface sediment layer $(0-10 \mathrm{~cm})$ surrounding rhizosphere of $P$. australis 


\section{3 沉积物可转化态氮含量的时间变化规律}

随着培养时间推移, 沉积物 TF-N 含量总体呈逐步递增趋势, 就沉积物 TF-N 均值大小排列顺序为 IMOF-N > OSF-N $>$ IEF-N $>$ CF-N ; 相反, 沉积物 NTF-N 含量显著降低 (图 4). 沉积物 IEF-N 和 OSF-N 含量出现先降低、后 增大的变化趋势, 分别在第 90 和 60 天达到极小值, 降幅分别为 $20.0 \%$ 和 $65.5 \%$; 在第 120 天, 对比初始含 量, 分别增加了 1.10 和 1.40 倍. 沉积物 CF-N 和 IMOF-N 含量 (除第 60 天外) 呈现逐渐递增的规律, 在第 120 天, 沉积物 CF-N 含量较初始值增加了 $63.7 \mathrm{mg} / \mathrm{kg}$, 是第 0 天的 3.40 倍; 沉积物 IMOF-N 含量较初始含量增加 $924 \mathrm{mg} / \mathrm{kg}$ (3.60 倍), 值得注意的是, IMOF-N 含量却在第 60 天达到极大值, 为 $1246 \mathrm{mg} / \mathrm{kg}$.
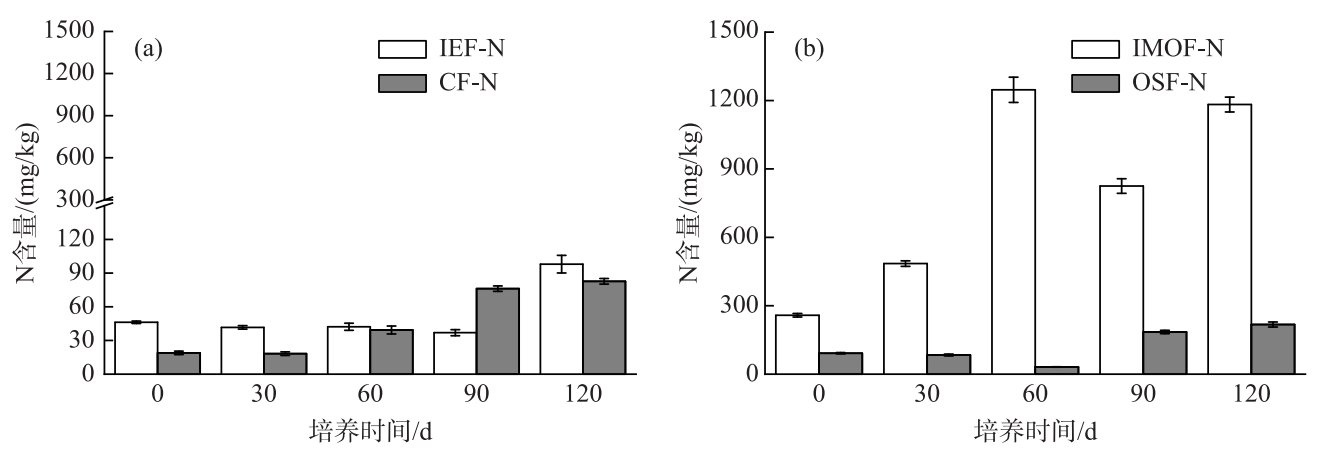

图 4 芦苇根际表层沉积物 $(0 \sim 10 \mathrm{~cm})$ 可转化态氮含量变化规律

Fig.4 Variations of exchangeable N contents including IEF-N, CF-N (a) and IMOF-N, OSF-N (b) in the surface sediment layer $(0-10 \mathrm{~cm})$ surrounding rhizosphere of $P$. australis

\section{4 沉积物氮与芦苇生物量变化的相关关系}

在整个模拟实验期间, 分别跟踪测定了芦苇总生物量、地下部生物量和细根生物量, 总体而言, 三者均 随着培养时间延长呈现指数型增长, 分别从 12.1、9.75 和 $1.29 \mathrm{~g}$ 增长到 $183 、 128$ 和 $31.5 \mathrm{~g}$ (图 5). 进一步分 析芦苇生物量与沉积物氮含量变化的相关性, 结果表明, 尽管沉积物 TN 与芦苇生物量变化间均未达到显著 相关, 而沉积物 TN 含量与芦苇生物量间却呈现出明显的负相关关系; 沉积物 $\mathrm{NH}_{4}^{+}-\mathrm{N}$ 含量与芦苇生物量变 化间呈正相关关系;沉积物 $\mathrm{NO}_{2}^{-}-\mathrm{N}$ 含量同步显示与芦苇生物量呈负相关关系. 沉积物 $\mathrm{NO}_{3}^{-}-\mathrm{N}$ 含量与芦苇总 生物量、地下部生物量和细根生物量呈显著正相关关系 $(P<0.05)$. 深人分析了沉积物 TF-N 含量与芦苇生物 量间的相关关系发现, 沉积物 TF-N 含量均随着芦苇生物量的增加而增加 (图 5), 其中 IEF-N、OSF-N 含量与 芦苇细根生物量呈显著正相关关系 $(P<0.05) ; \mathrm{CF}-\mathrm{N}$ 含量与芦苇总生物量、地下部生物量和细根生物量间均 呈显著正相关关系 $(P<0.05)$.

\section{3 讨论}

沉积物不仅对水生植物起到固持作用, 更重要的是为水生植物的生长发育提供 N、P、有机质等大量营 养元素和微量元素等养分物质, 而根着水生植物主要从栖生的沉积物中吸收养分物质用于自身生长 ${ }^{[18,25]}$. 本研究中, 沉积物 TN 含量随着培养时间延长出现逐渐下降趋势, 对比第 0 天实验结束时沉积物 TN 含量减 少了约 50.0\% (图 3), 这是由芦苇主要从沉积物中获取大量氮素用于自身生长发育造成的; 其次, 沉积物 TN 和芦苇总生物量统计分析结果表明 (图 5), TN 含量和总生物量呈显著负相关关系, 随着芦苇总生物量的增 加, 总氮含量逐渐递减, 进一步佐证了沉积物总氮含量降低主要是由于芦苇的吸收利用, 并非沉积物中微生 物脱氮过程发挥主导作用.

随着培养时间推移, 沉积物中 $\mathrm{NH}_{4}^{+}-\mathrm{N}$ 含量大致与 $\mathrm{NO}_{3}^{-}-\mathrm{N}$ 和 $\mathrm{NO}_{2}^{-}-\mathrm{N}$ 含量呈负相关关系 (图 3, 图 5). 沉积 物 $\mathrm{NH}_{4}^{+}-\mathrm{N}$ 含量从第 0 天到第 $90 \mathrm{~d}$ 呈现逐渐下降的趋势, 其原因有两点: 一是芦苇对于 $\mathrm{NH}_{4}^{+}-\mathrm{N}$ 的吸收潜力最 大, 芦苇优先利用 $\mathrm{NH}_{4}^{+}-\mathrm{N}^{[16]}$, 从而造成其在前 $90 \mathrm{~d}$ 含量有所下降; 二是植物光合作用会通过根系、茎叶向沉 积物释放氧气(图 2), 造成沉积物氧化还原电位的升高, 促进硝化反应的进行, 从而造成 $\mathrm{NH}_{4}^{+}-\mathrm{N}$ 含量降 

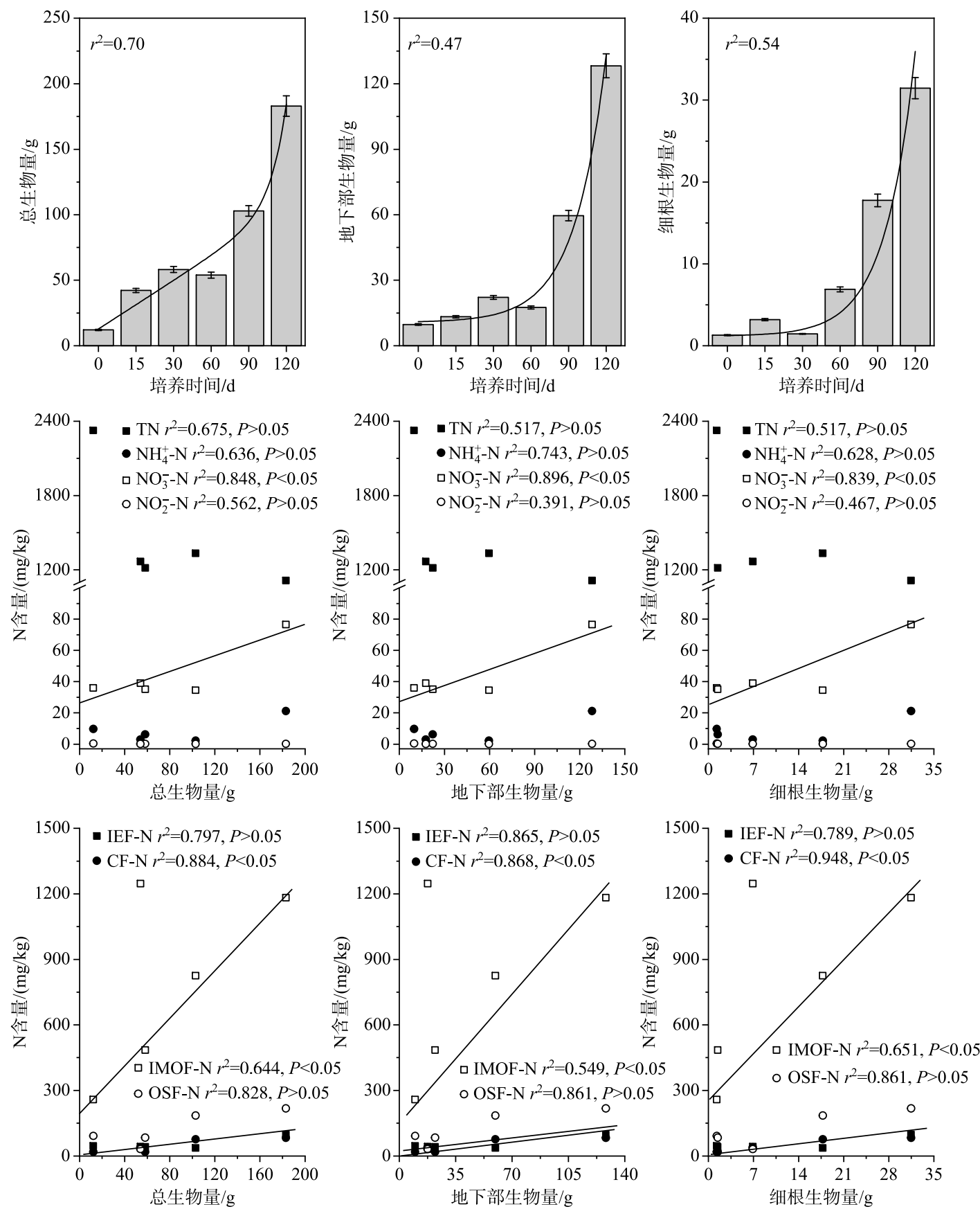

图 5 芦苇生物量与表层沉积物 $(0 \sim 10 \mathrm{~cm}) \mathrm{TN}$ 、DIN 及可转化态氮含量的相关关系

Fig.5 Correlations between the biomass of $P$. australis including total biomass, belowground biomass and fine root biomass and changes in TN, DIN and exchangeable $\mathrm{N}$ contents in surface sediments $(0-10 \mathrm{~cm})$

低 ${ }^{[5]}$. 沉积物 $\mathrm{NO}_{3}^{-}-\mathrm{N}$ 含量出现震荡波动变化规律 (图 3), 从第 0 天到第 $60 \mathrm{~d}$ 逐渐增加, 且在第 120 天出现极 大值, 这可能是由于芦苇通过光合作用经根系泌氧到根区周边沉积物中, 从而造成根际沉积物氧化还原电 位提高, 促使沉积物中 $\mathrm{NH}_{4}^{+}-\mathrm{N}$ 向 $\mathrm{NO}_{3}^{-}-\mathrm{N}$ 转化的硝化过程增强, 有利于低价态的氮向高价态的氮形态转化, 
所以 $\mathrm{NO}_{3}^{-}-\mathrm{N}$ 含量前 $60 \mathrm{~d}$ 有增长的趋势 (图 3). 值得注意的是, 第 120 天沉积物 $\mathrm{NH}_{4}^{+}-\mathrm{N}$ 和 $\mathrm{NO}_{3}^{-}-\mathrm{N}$ 含量出现极 大值 (图 3), 该现象可能归因于以下几个过程: 1) 芦苇枯枝败叶通过腐解过程向间隙水和上覆水体中释放 出大量的氨氮 ${ }^{[26-30]}$, 而 $\mathrm{NH}_{4}^{+}-\mathrm{N}$ 极易被沉积物中的无机胶体颗粒所吸附而埋藏在表层沉积物中 $\left.{ }^{[31]} ; 2\right)$ 可能受 芦苇一沉积物系统 TIN 迁移转化过程的影响, 随培养时间延长, 气温逐渐降低, 抑制了沉积物反硝化细菌的 活性, 反硝化反应速率大幅度减慢 ${ }^{[29]}$. 此外, 沉积物中 $\mathrm{NO}_{2}^{-}-\mathrm{N}$ 含量随芦苇生长逐渐下降, 进一步证明了沉积 物 $\mathrm{NO}_{3}^{-}-\mathrm{N}$ 含量在第 120 天达到极大值部分是由于 $\mathrm{NO}_{2}^{-}-\mathrm{N}$ 的转化.

在整个模拟实验过程中, 沉积物 IEF-N、CF-N、IMOF-N、OSF-N 共同组成沉积物中的 TF- $\mathrm{N}^{[32]}$, 沉积物 TF-N 含量均大体呈现增加趋势 (图 5), 这主要是由于芦苇根际过程使得沉积物惰性态氮出现活化现象, 整 个培养实验沉积物 NTF-N 发生大幅下降从侧面佐证了沉积物氮存在被激活的过程(图 3,4). IEF-N 是 TF-N 中与沉积物结合程度最为松散的氮形态, 极易参加水体一沉积物系统氮的生物地化循环过程, 是 TF-N 中最 为活跃的一种氮形态 ${ }^{[33]}$. 从培养实验开始至第 60 天, 沉积物 IEF-N 逐渐增加, 该部分氮主要由 $\mathrm{NH}_{4}^{+}-\mathrm{N}$ 和 $\mathrm{NO}_{3}^{-}-\mathrm{N}$ 组成, 其中 $\mathrm{NH}_{4}^{+}-\mathrm{N}$ 的平均含量为 $8.50 \mathrm{mg} / \mathrm{kg}$, 而 $\mathrm{NO}_{3}^{-}-\mathrm{N}$ 的平均含量为 $44.3 \mathrm{mg} / \mathrm{kg}, \mathrm{NO}_{3}^{-}-\mathrm{N}$ 在 IEF-N 中 占主导地位, 所以 IEF-N 的变化趋势和 $\mathrm{NO}_{3}^{-}-\mathrm{N}$ 相似, 提升的根区沉积物氧化环境促使 $\mathrm{NH}_{4}^{+}-\mathrm{N}$ 向高价态的 $\mathrm{NO}_{3}^{-}-\mathrm{N}$ 转化 ${ }^{[34]}$, 沉积物 $\mathrm{NO}_{3}^{-}-\mathrm{N}$ 含量增加进一步证实该过程 (图 3).

CF-N 为碳酸盐结合态氮 ${ }^{[35]}$, 其结合能力稍强于 IEF-N, 其含量主要和沉积物中碳酸盐含量有关. 在整 个培养过程中, 沉积物 CF-N 含量随芦苇生长逐渐增加 (图 3), 这与芦苇根际有机酸分泌调节过程紧密相 关, 根际短暂的酸性环境将直接影响沉积物中 $\mathrm{CaCO}_{3}$ 的矿化作用 ${ }^{[36]}, \mathrm{CaCO}_{3}$ 在偏酸性的环境下容易分解进 人水体中, 导致 $\mathrm{CaCO}_{3}$ 吸附的 TIN 也会释放到水体中, 从而造成 CF-N 含量下降 ${ }^{[37]}$, 综合第 60 天沉积物 CF-N 含量到达极小值和芦苇在第 60 天光合作用强度达到最大值的证据, 从侧面证实了沉积物 CF-N 存在分 解过程. 另一方面, 由于芦苇要通过光合作用提升了水中的 $\mathrm{pH}$, 造成溶解到水中的 $\mathrm{Ca}^{2+} 、 \mathrm{CO}_{3}^{2-}$ 离子重新结合 并沉降到表层沉积物中, 重新结合的 $\mathrm{CaCO}_{3}$ 再次吸附水体中 TIN 到沉积物表面, $\mathrm{CF}-\mathrm{N}$ 含量升高, 所以在芦苇 恢复第 90 天 CF-N 含量均大幅上升,并在第 120 出现极大值.

IMOF-N 和铁锰氧化物的结合能力相当, 其释放能力较 IEF-N、CF-N 更弱 ${ }^{[34]}$. 本研究发现沉积物 IMOF-N 是 TF-N 的主要组成形态, 含量基本呈现逐渐增加的趋势, 在第 60 天达到极大值, 这可能有以下两个原因: 一是芦苇生长过程不断从沉积物中获取氮等营养物质, 同时根系过程促使沉积物活性更低的氮向活性高的 相态转变, 提高了沉积物氮的活性, 而根际环境趋向氧化使 $\mathrm{Fe}^{2+}$ 转化为 $\mathrm{Fe}^{3+}$, 形成铁锰化合物, 进而吸附了水 体中的无机形态氮, 由此造成沉积物 IMOF-N 含量增加 ${ }^{[38]}$; 二是芦苇衰亡后向水体释放的 TIN 容易被吸附 沉降到沉积物表面, 增加了 IMOF-N 含量. 有趣的是, 第 30 天沉积物 IMOF-N 含量出现极小值, 主要是由于 芦苇为满足自身快速生长, 对沉积物氮的需求量也达到最高水平, 并且芦苇对沉积物氮的吸收利用速率远 高于活化过程 (图 5).

OSF-N 是 4 种 TF-N 中最难以释放以及最为稳定的一种氮形态 ${ }^{[39]}$, 其含量与沉积物氧化还原状态和 TOC 含量呈正相关关系 ${ }^{[40]}$, 培养实验开始时, 沉积物较高的 TOC 含量积累了一定量的 OSF-N. 值得注意的 是, 沉积物 OSF-N 在第 60 天达到极小值, 从实验开始至结束逐渐增加. 前者原因是: 随着芦苇不断生长, 光 合作用向水体释放大量的氧, 对沉积物氮的需求量持续增大, 降低了沉积物 OSF-N 稳定性, 从而造成在芦苇 恢复第 60 天的时候含量急剧下降 (图 2,4). 后者原因是: 从第 90 天至第 120 天, 芦苇进人衰亡期,其腐败的 枯枝烂叶会向水体中释放大量的氮素、有机物质, 造成水体中有机物含量大幅度增加, 与之结合的 OSF-N 也 相应增加, 从而造成了沉积物 OSF-N 含量出现升高现象.

需要指出的是, 沉积物 TF-N 含量的时间变化还同步受到不同形态转化过程的影响, 其中沉积物 NTF-N 的活化分解过程至关重要 ${ }^{[32]}$. 研究发现, 沉积物 TN 含量在第 0 天为最大值, 而后逐渐降低, 并在第 120 天 总氮含量达到极小值, 但 TF-N 呈现增加的趋势, 该证据表明沉积物 TF-N 含量增加主要是由芦苇为满足自 身生长的营养需求而对沉积物活性更低的 NTF-N 的活化分解过程主导的.

总体而言, 通过分析芦苇恢复过程下沉积物 TN TIN 和 TF-N 含量及形态变化特征, 发现芦苇恢复能够 有效削减富营养化水体的内源污染强度, 同时改变了沉积物 $\mathrm{pH}$ 、氧化还原状态等关键指标 ${ }^{[5,38]}$. 但芦苇调亡 分解阶段将会向上覆水体释放大量的营养物质, 进而造成水体的二次污染. 基于湖泊生态系统恢复力稳定 
性视角,从湖泊水体 $\mathrm{N} 、 \mathrm{P}$ 营养物管理策略出发,建议采用物理收割和生态管控等湖泊工程学手段对调亡衰 老的芦苇枯立物进行定期收割 (如过冬枯立物集中采收、污染物淤积区开展定期生态疏浚等管控措施), 清 理凋落在沉积物表面的枯枝败叶, 进一步提升芦苇恢复工程对富营养化水体的修复效果及长效稳态机制 ${ }^{[8]}$.

\section{4 结论}

通过为期 $120 \mathrm{~d}$ 的水槽模拟和沉积物柱芯培养实验, 结果表明,芦苇完整生长过程明显提高了沉积物氮 的活性程度, 使得沉积物 TN 和 NTF-N 含量显著降低, 而沉积物 TF-N 含量却出现逐渐增大趋势, 沉积物 TF-N 和 TIN 含量在第 120 天分别较第 0 天增加了 1.10 和 2.80 倍. 进一步分析沉积物 TF-N 变化, 发现芦苇 生长发育提高了沉积物 IEF-N、CF-N、IMOF-N 和 OSF-N 含量,第 120 天各 TF-N 含量相比第 0 天分别增加了 $1.10 、 3.40 、 3.60$ 和 1.40 倍. 基于 Pearson 相关性分析, 发现芦苇生物量是驱动沉积物 TN、TIN 和 TF-N 变化的 重要因子. 为最大限度地降低内源污染负荷, 提高富营养化湖泊植被恢复工程的修复效果, 采取综合的湖泊 物理一生态工程手段来有效管控越冬期芦苇枯落物显得至关重要.

\section{5 参考文献}

[ 1 ] Zhang YL, Jeppesen E, Liu XH et al. Global loss of aquatic vegetation in lakes. Earth-Science Reviews, 2017, 173: 259265. DOI: 10.1016/j.earscirev.2017.08.013.

[ 2 ] Huisman J, Codd GA, Paerl HW et al. Cyanobacterial blooms. Nature Reviews Microbiology, 2018, 16( 8) : 471-483. DOI: $10.1038 / \mathrm{s} 41579-018-0040-1$.

[ 3 ] Paerl HW, Gardner WS, McCarthy MJ et al. Algal blooms: Noteworthy nitrogen. Science, 2014, 346(6206): 175. DOI: 10.1126/science.346.6206.175-a.

[ 4 ] Jin XC. Analysis of eutrophication state and trend for lakes in China. Journal of Limnology, 2003, 62(1s) : 60. DOI: 10. 4081/jlimnol.2003.s1.60.

[ 5 ] Xu QJ, Jin XC, Yan CZ. Macrophyte degradation status and countermeasures in China. Ecology and Environment, 2006, 15(5) : 1126-1130. [许秋瑾，金相灿，颜昌宙. 中国湖泊水生植被退化现状与对策. 生态环境, 2006, 15(5): 1126-1130.]

[ 6 ] Paerl HW, Barnard MA. Mitigating the global expansion of harmful cyanobacterial blooms: Moving targets in a human- and climatically-altered world. Harmful Algae, 2020, 96: 101845. DOI: 10.1016/j.hal.2020.101845.

[ 7 ] Qin BQ, Song YZ, Gao G. The role of periphyton in the transformation process of algae-grass ecosystem in shallow eutrophication lakes. Science in China: Series C, 2006, 36(3) : 283-288. [秦伯强, 宋玉芝, 高光. 附着生物在浅水富营养化 湖泊藻-草型生态系统转化过程中的作用. 中国科学: C 辑, 2006, 36(3) : 283-288.]

[ 8 ] Scheffer M, Carpenter S, Foley JA et al. Catastrophic shifts in ecosystems. Nature, 2001, 413(6856) : 591-596. DOI: 10.1038/35098000.

[ 9 ] Liu XH, Zhang YL, Shi K et al. Mapping aquatic vegetation in a large, shallow eutrophic lake: A frequency-based approach using multiple years of MODIS data. Remote Sensing, 2015, 7(8) : 10295-10320. DOI: 10.3390/rs70810295.

[10] Yu JH,Zhong JC, Zhang YS et al. Fine-scale remobilization of phosphorus by rooted macrophytes (Phragmites australis) growth in lake sediments: Evidence from a holistic growth period simulation study. Journal of Soils and Sediments, 2020, 20(3) : 1782-1792. DOI: 10.1007/s11368-019-02502-4.

[11] Ren WJ,Tian ZF, Ning GH et al. Purification efficiency of four species submerged macrophytes for the eutrophic water in Baiyangdian Lake. Ecology and Environmental Sciences, 2011, 20(2) : 345-352. [任文君, 田在锋, 宁国辉等. 4 种沉 水植物对白洋淀富营养化水体净化效果的研究. 生态环境学报, 2011, 20(2) : 345-352.]

[12] Xing T, Li JX, Li BB et al. Effects of macrophytes on gaseous nitrogen emissions and nitrogen removal from sediments in a shallow eutrophic lake. Chinese Journal of Ecology, 2018, 37 (3) : 771-778. DOI: 10.13292/j.1000-4890.201803.030. [邢涛, 李俊雄, 李彬彬等. 水生植物对草型富营养化湖泊气态氮排放及沉积物氮去除的影响. 生态学杂志, 2018, 37(3): 771-778.]

[13] Chen RL, Barko JW. Effects of freshwater macrophytes on sediment chemistry. Journal of Freshwater Ecology, 1988, 4 (3) : 279-289. DOI : 10.1080/02705060.1988.9665177.

[14] Zhao XG. Effect of emergent plants on circulation of nitrogen and phosphorus of eutrophic lakes [Dissertation]. Tianjin: 
Tianjin University, 2011. [ 赵旭光. 挺水植物对富营养化湖泊水体中氮磷循环的影响 [学位论文]. 天津: 天津大 学, 2011.]

[15] Kong XL, Ye C, Li CH et al. Effect on nitrogen transfer and migration by Vallisneria natans (Lour.) Hara in water-sediment-submerged macrophytes system. China Environmental Science, 2015, 35(2) : 539-549. [孔祥龙, 叶春, 李春华等. 苦草对水-底泥-沉水植物系统中氮素迁移转化的影响. 中国环境科学, 2015, 35(2): 539-549.]

[16] Bao XM, Chen KN, Fan CX. Effects on nitrogen and phosphorus distribution in interstitial water and sediment-water nitrogen and phosphorus release with growing of submerged macrophytes. J Lake Sci, 2006, 18(5) : 515-522. DOI: 10.18307/ 2006.0513. [包先明, 陈开宁, 范成新. 沉水植物生长对沉积物间隙水中的氮磷分布及界面释放的影响. 湖泊科 学, 2006, 18(5): 515-522.]

[17] Hu HW, Fu YM, Liu P et al. Influence of the decomposition of emergent plant residues on physical property of Lake Baigui wetland deposition. Journal of Henan Polytechnic University: Natural Science, 2020, 39(5) : 36-42. [胡红伟, 扶 咏梅, 刘盼等. 挺水植物残体腐解对白龟湖湿地沉积物理化性质的影响. 河南理工大学学报: 自然科学版, 2020, $39(5): 36-42$.]

[18] Barko JW, Smart RM. Sediment-based nutrition of submersed macrophytes. Aquatic Botany, 1981, 10: 339-352. DOI: 10. 1016/0304-3770 ( 81 ) 90032-2.

[19] Wang SR, Jin XC, Cui Z et al. Effects of submerged plant on the concentrations of different nitrogen species in water-sediment interface. Environmental Chemistry, 2006, 25(5): 533-538. [王圣瑞, 金相灿, 崔哲等. 沉水植物对水-沉积物 界面各形态氮含量的影响. 环境化学, 2006, 25(5): 533-538.]

[20] Yu JH,Zhong JC, Chen QW et al. An investigation of the effects of capping on internal phosphorus release from sediments under rooted macrophytes (Phragmites australis) revegetation. Environmental Science and Pollution Research, 2018,25 (25) : 24682-24694. DOI: 10.1007/s11356-018-2432-1.

[21] Jin XC, Tu QY eds. Specifications for lake eutrophication survey: 2nd Edition. Beijing: China Environmental Science Press, 1990. [ 金相灿, 屠清瑛. 湖泊富营养化调查规范: 第 2 版. 北京: 中国环境科学出版社, 1990. ]

[22] Ma HB, Song JM, Lv XX et al. Nitrogen forms and their functions in recycling of the Bohai Sea sediments. Geochimica, 2003, 32(1) : 48-54. DOI: 10.19700/j.0379-1726.2003.01.007. [马红波, 宋金明, 吕晓霞等. 渤海沉积物中氮的形 态及其在循环中的作用. 地球化学, 2003, 32(1): 48-54.]

[23] Zhao HC, Wang SR, Jiao LX et al. Characteristics of temporal and spatial distribution of the nitrogen forms in the sediments of Erhai lake. Research of Environmental Sciences, 2013, 26(3) : 235-242. DOI: 10.13198/j.res.2013.03.14.zhaohch.007. [ 赵海超, 王圣瑞, 焦立新等. 洱海沉积物中不同形态氮的时空分布特征. 环境科学研究, 2013, 26(3): 235-242.]

[24] Jiang X, Wang SH eds. Manual of sediment quality investigation and assessment. Beijing: Science Press, 2012. [姜霞, 王书航. 沉积物质量调查评估手册. 北京: 科学出版社, 2012.]

[25] Liu Y, Yi QT, Chen QW et al. The spatial distribution of nitrogen species in surface sediment in the west river networks of the Taihu Lake Basin, China. Acta Scientiae Circumstantiae, 2015, 35(12) : 3890-3897. DOI: 10.13671/j.hjkxxb.2015. 0412. [刘芸, 易齐涛, 陈求稳等. 太湖西部河网中沉积物氮的空间分布特征. 环境科学学报, 2015, 35(12)： 3890-3897.]

[26] Lei ZX, Xu DL, Gu JG et al. Distribution characteristics of aquatic macrophytes and their effects on the nutrients of water and sediment in Taihu Lake. Journal of Agro-Environment Science, 2008, 27(2) : 698-704. [雷泽湘, 徐德兰, 顾继光 等. 太湖大型水生植物分布特征及其对湖泊营养盐的影响. 农业环境科学学报, 2008, 27(2): 698-704.]

[27] Qi MX, Wang HP, Chen J. Decomposition of Phragmites australis and Typha angustifolia and their effects on the water quality in winter and spring. J Lake Sci, 2017, 29(2) : 420-429. DOI: 10.18307/2017.0218. [戚美侠, 王红萍, 陈杰. 冬、春季芦苇 (Phragmites australis) 和狭叶香蒲 (Typha angustifolia) 的腐解过程及其对水质的影响. 湖泊科学, $2017,29(2): 420-429$.

[28] Xie YJ, Xie YH, Xiao HY et al. Controls on litter decomposition of emergent macrophyte in Dongting Lake wetlands. Ecosystems, 2017, 20(7) : 1383-1389. DOI: 10.1007/s10021-017-0119-y.

[29] Luo P, Tong X, Liu F et al. Nutrients release and greenhouse gas emission during decomposition of Myriophyllum aquaticum in a sediment-water system. Environmental Pollution, 2020, 260: 114015. DOI: 10.1016/j.envpol.2020.114015.

[30] Wei YY, Zhang MY, Cui LJ et al. Winter decomposition of emergent macrophytes affects water quality under ice in a tem- 
perate shallow lake. Water, 2020, 12(9) : 2640. DOI: 10.3390/w12092640.

[31] Wang SR, Jin XC, Jiao LX et al. Nitrogen fractions and release in the sediments from the shallow lakes in the middle and lower reaches of the Yangtze River area, China. Water, Air, and Soil Pollution, 2008, 187(1/2/3/4) : 5-14. DOI: 10. 1007/s11270-007-9453-6.

[32] Wu SL, Xia PH, Lin T et al. Contents and distribution characteristics of nitrogen forms in sediments of Guizhou Lake Caohai under different water level levels. J Lake Sci, 2019, 31(2) : 407-415. DOI: 10.18307/2019.0210. [吴胜利, 夏品 华, 林陶等. 贵州草海不同水位梯度下沉积物氮赋存形态及分布特征. 湖泊科学, 2019, 31(2): 407-415.]

[33] Zhang YN, Ma QM, Yue ZK et al. Study of nitrogen forms in the sediments from Dongchang Lake. Environmental Chemistry, 2013, 32(3) : 459-465. [张亚楠, 马启敏, 岳宗恺等. 东昌湖表层沉积物中氮的赋存形态. 环境化学, 2013, 32(3) : 459-465.]

[34] Jin J, Yuan XY, Chen SW et al. Distribution of nitrogen forms in suspended sediments and surface sediments of East Tiaoxi River, upper reaches of Taihu Basin and their influence factors. J Lake Sci, 2017, 29(3) : 594-603. DOI: 10. 18307/2017.0308. [ 金晶, 袁旭音, 陈诗文等. 太湖流域上游东苕溪干流沉积物和悬浮物的氮形态分布及影响因 素. 湖泊科学, 2017, 29(3): 594-603.]

[35] Wang M, Liu Y, Zheng BH et al. Nitrogen forms in surface sediments of urban river and their influence factors: A case study of Qingyi River in Xuchang City. China Environmental Science, 2014, 34(3): 720-726. [王梅, 刘琰, 郑丙辉等. 城市内河表层沉积物氮形态及影响因素——以许昌清潩河为例. 中国环境科学, 2014, 34(3): 720-726.]

[36] Yu BS, Lai XY. Carbonic acid system of groundwater and the solubility of calcite during diagenesis. Acta Sedimentologica Sinica, 2006, 24(5): 627-635. [于炳松, 赖兴运. 成岩作用中的地下水碳酸体系与方解石溶解度. 沉积学报, $2006,24(5): 627-635$.

[37] Bai JH, Ouyang H, Deng W et al. Spatial distribution characteristics of organic matter and total nitrogen of marsh soils in river marginal wetlands. Geoderma, 2005, 124(1/2) : 181-192. DOI: 10.1016/j.geoderma.2004.04.012.

[38] Zhou TY, Li HS, Jian HM et al. Nitrogen forms in surface sediment in the Yangtze River estuary and adjacent area. Marine Environmental Science, 2018, 37(2) : 281-286. [周天宇, 李浩帅, 简慧敏等. 长江口及邻近海域表层沉积物中氮形 态的研究. 海洋环境科学, 2018, 37(2): 281-286.]

[39] Liu H, Kong WW, Wang XF et al. Temporal and spatial characteristics and influencing factors of nitrogen morphology in surface sediments of liangtan river, Chongqing. Journal of Soil and Water Conservation, 2019, 33(6) : 332-341. [刘欢, 孔维苇, 王晓锋等. 重庆梁滩河表层沉积物氮形态时空特征及影响因素. 水土保持学报, 2019, 33(6): 332-341.]

[40] Zhang JW, Wei J, Liu L et al. Distribution characteristics and pollution assessment of nutrients in Hengshui Lake sediments. Environmental Science, 2020, 41(12) : 5389-5399. DOI: 10.13227/j.hjkx.202004237. [张嘉雯, 魏健, 刘利等. 衡水湖沉积物营养盐形态分布特征及污染评价. 环境科学, 2020, 41(12) : 5389-5399.] 